\title{
The Academic Usage of Social Networking Sites by the University Students of Tamil
}

Nadu

\section{R. Subramani, Periyar University, India}

\begin{abstract}
The growing popularity of social media has influenced researchers to start investigate the communication and interaction between people using these media. University students are active users of social media for academic purpose as well as for personal use. As this social media phenomenon is continuing to grow at a faster pace, it is important to understand the effects it has on students. Given its popularity, researchers have considerable concerns about the effects of social media on students. Many studies gave an overview of social media and its popularity, usage, and impact among students. Since each day new technology evolve in social media, this study shall also examine the components and factors that influence our students' present social media usage and its impact. The social media needs to be understood more comprehensively for better understanding of factors that influence the usage, acceptance, and behavior of the Indian students. Despite the widespread use of social media, little is known about its impact on Indian students; hence this study will provide a better knowledge about the perception and impact of social media. The study envisioned to examine the academic use of social media applications by university students, and to study the usage of various academic applications of social media by the university students. Survey method was employed to study the academic usage of the social media by the university students and exhaustively collects samples from the state universities of Tamil Nadu. The population of the study consisted of thirteen major discipline of students in Doctoral, M Phil and Master Branches. The sample size of the study comprised of 482 students selected through convenient sampling technique. The structured questionnaire was used for data collection.
\end{abstract}

Keywords: Social media, Social network sites, University, Students, Usage 


\section{Introduction}

In the last ten years, the communication environment around the world has changed significantly. The emergence of various forms of interpersonal communication has brought people closer, notably e-mail, instant messaging, social networking sites, etc. India has about 230 million active internet users, which is world's third largest internet user base. The fastest growth in social media usage is happening in India with the increased user percentage of 37.4 in 2013 . More than $75 \%$ of internet users in India are in the age group 18-35 years.

Social media are those used to communicate with more than one person at a time. Social media include social networking sites like Facebook, and MySpace, micro-blogging sites like Twitter and Tumblr, media sharing sites like YouTube and Flickr, blogs and other communication within virtual worlds. The rapid uptake of both social media and social networking site practices by young students signifies an important shift in their use of internet primarily for information and entertainment to one of communication.

A social network comprises of a set of individuals who are interconnected through certain relationships such as friendship, co-working or information exchange (Garton, Haythornthwaite \& Wellman, 1997). In its traditional form, members of a social network communicate through face-to-face conversations, telephone calls and letters. However, as information technology advanced, so did online social networks (Chou \& Chou, 2009). Indeed, online social-networking services have been a feature of the Internet, in one form or another, since the inception of the World Wide Web. For example, electronic-mail (e-mail) messages were used by early Internet adopters to establish various patterns of online communication where users could interact with one another by sharing photos or discussing about several issues (Mislove et al., 2007; Treese, 2008). However, a new generation of social technology has recently emerged with the potential of delivering more effective support to users' social lives. This new generation of Web-based technology, known to Web developers as Web 2.0, has quickly gained widespread popularity by enabling millions of users worldwide to create content, tag photographs, share videos, write blogs, and make acquaintances through the Web on a daily basis (Liccardi et al., 2007). As a result of these technological advances in Web technology and the development of Web 2.0, the nature of online communication, socialization, and privacy has changed (Williams \& Merten, 2008). 


\section{Characteristics of Social-networking Sites}

According to Mazman and Usluel (2010), the characteristics (e.g., personalized content, information sharing and collaboration) of a social-networking site differentiates it from other Websites. Similarly, Dube (2012) identified five important characteristics of a socialnetworking site that distinguish it from a regular Web site. The characteristics are as follows;

User-base: While regular Web sites are based on content updated by a single user or administrator who determines the direction of future updates for Web visitors, socialnetworking sites are built and directed by users. Consequently, without users, online social networks will be void of conversations and content.

Interactivity: Social-networking sites are interactive due to the availability of chat rooms, discussion forums, and network-based gaming applications. Therefore, unlike regular Web sites, online social networks provide a way to connect and have fun with contacts.

Community-driven: Social-networking sites are built on and thrive from community oriented concepts. This means that unlike regular Web sites, online social networks are based on users' common beliefs or hobbies. Therefore, sub-communities of people who share commonalities can be discovered based on interest-based communities, such as university alumni and animal welfare groups.

Relationships: Unlike regular Web sites, social-networking sites thrive on relationships. The more relationships a user has within the network, the more established and influential he or she becomes within the network.

Emotion over content: Emotion is another important characteristic of social networking sites. While regular Web sites are focused primarily on providing information to visitors, online social networks provide users with emotional security and a sense of closeness to contacts such as friends and family.

Furthermore, in a study to determine why social-networking applications are successful, $\mathrm{Ou}$ et al. (2011) identified six additional characteristics of online social networks. These include identity management (which allows users to construct a social identity to present to other 
users in the form of a personal profile), information exchange (which allows connected users to exchange information directly or indirectly in a semi-structured manner [Chou \& Chou, 2009]), expert finding (the use of search functionality as a way to identify knowledge [Richter \& Koch, 2008]), context awareness (common context with other users such as common interests about the same university [Richter \& Koch, 2008]), contact management (maintenance of the digital personal network by tagging people, allowing access or restricting access to profiles [Richter \& Koch, 2008]), and, network awareness (the awareness of activities by informing people about one's current status or changes [Richter \& Koch, 2008]).

\section{Academic Usage of Social Network Sites}

Mazman and Usluel (2010) described educational usage as an important benefit of socialnetworking sites. They portrayed Facebook, a popular social-networking site, as a useful educational tool due to its structure and various utilities, such as providing users with intentional or spontaneous learning opportunities by bringing people together around shared interests, exchanging information, sharing ideas, discussion topics and collaborating. In particular, Mazman and Usluel argue that social-networking sites support collaborative learning, engage individuals in critical thinking, enhance communication and writing skills through activating users' work in personalized environments. Mazman and Usluel also cite that social networks are pedagogical tools because people can use them for connectivity and social support, collaborative information discovery and sharing, content creation, and knowledge and information aggregation and modification. They described the educational benefits of social-networking sites in three ways.

Facilitation: Social-networking sites facilitate communication between students and instructors, and provide information about resources and links related to course materials. Furthermore, they allow students to follow announcements about classes and courses, departments or schools, delivery of homework and assignments by lecturers.

Collaboration: Students can take part in collaborative learning by exchanging ideas, sharing information and working together based on interests, and needs. Examples of studentcollaboration include taking part in activities such as joining academic groups related to their schools, departments or classes and carrying on group works by sharing homework, projects, and ideas. 
Resource/material sharing: Resource sharing consist of activities like exchanging multimedia resources such as, videos, audio materials, animated videos, resources and documents. With features that allow users to upload photos and videos, and add or 'follow' links to external Web pages, social-networking sites provide students with audio, as well as visual materials and resources. Therefore, students can share project materials, and documents, as they exchange ideas and information on social- networking sites.

\section{Review of Literature}

Social networks have experienced a massive growth in membership in recent years (Barker, 2009), particularly among university students (Lenhart \& Madden, 2007). Over 90\% of young adults (18-25 year olds) of university age are reported to have an active profile on a social networking site in the United Kingdom (Comscore, 2011). Similarly, Salaway, Caruso and Nelson (2008) stated that social-networking sites now constitute an integral part of daily communication practices for many university students.

Kumar and Kumar (2013) found that Facebook was the most popular social media among post graduate and research students in an Indian university. Twitter was second most popular among those students. Singh and Kumar (2013) from Punjab University conducted a study to measure the usage of social networking among their research students. The findings of the study shows that majority of the respondents were found to be aware and making use of social media in their research work. Their study also reveals that Facebook is the most popular social networking sites among the research scholars.

According to new research released by Ipsos Open Thinking Exchange (2013), American youths spend average 3.8 hours a day on social networking from a computer, mobile phone and/or tablet. The study by Walsh et al. (2013) found that female first-year college students spend nearly 12 hours a day using social media on average. In addition they found a correlation between lower GPAs and higher social media use. The researchers also found the use of some types of social media has beneficial effects, like helping students establish a sense of identity and build networking skills.

Another study was conducted by Stollak et al. (2011) found that time spent on social networking sites was mostly on Facebook (78.3\%) majority of students (77.2\%) spent more 
than 30 minutes a day. A study by Internet \& Mobile Association of India (2011) shows that more than $75 \%$ of internet users in India are school and college going students. Among them, $89 \%$ of students use it for email and social networking. According to the study done by Manjunatha (2013), 80 percent of the students spending considerable amount of time on using social networking sites regularly. Majority of Indian college students (62.6\%) spent up to 10 hours per week of their time on using social networking and reportedly $17.5 \%$ of students spent more than 10 hours per week.

Whittemore School of Business and Economics recently conducted a survey of over 1,000 students. It was concluded that there is no correlation between how much time is spent on a social networking site and grades (Martin, 2009). A study by Karpinski and Kirschner (2010) found that frequent Facebook users have got slightly lower grades than less Facebook users. The average Facebook had a GPA of 3.0-3.5, while the non-user had a GPA of 3.5-4.0. In addition, the average Facebook user studied for 1-5 hours per week, while the non-Facebook user would study 11-15 hours per week. A study done by The University of New Hampshire shows that $63 \%$ of heavy users received high grades, compared to $65 \%$ of light users ( $\mathrm{U}$ of $\mathrm{NH}, 2009$ ). In addition, a majority of students use social networking for education and professional reasons apart from social connections and entertainment.

However, Karpinski focused on the relationship between time spent on Facebook and the academic performance of students. The overall finding indicated more time on Facebook equals slightly lower grades (San Miguel, 2009). A study conducted by Ohio State University reveals that college students who utilize more Facebook and spend less time on studying have lower grades than students who do not use Facebook (Kalpidou, Costin, \& Morris, 2011).

Since the formation of the Internet, users have shown an increasing willingness to produce a persistent digital identity that enables long-term social interactions (Gross \& Acquisti, 2005 \& Boyd \& Heer, 2006). A study by Francis (2013) concluded that constructive use of social media among college students is very low as just $10 \%$ of the students use it for their educational purpose while $77.5 \%$ use it for entertainment purpose. He also found out that there were no gender or age differences in term of social media usage of college students. 


\section{Methodology for the study}

This present study employed survey method as a research methodology to examine the usage of the various academic applications of social media by the university students of Tamil Nadu. The data was collected through a stratified random sampling from 482 students. The questionnaires were administered with the students and scholars who actively participate in internet. In this paper, the usage of academic applications of social media by the university students was alone taken for analysis and discussion.

\section{Findings and Discussion}

The researcher proposed to study the usage of academic applications by the university students and particularly envisioned to observe the downloading behavior of the students. How much percentage of academic applications such as Software's, video talks, audio books, electronic books, electronic journals, electronic magazines, research articles and PPT files were downloaded for the purpose of academic development was alone focused in this part. The collected data were analyzed and discussed in the following section.

\section{Table: 1: Software downloaded from the internet per day by the students}

This section of the research aimed to understand the software usage of the university students. The frequency of new software downloaded by the students was found. The collected data were presented in the below Table 1.

\begin{tabular}{|l|c|c|c|c|c|c|c|c|c|c|c|c|c|c|c|c|c|c|}
\hline $\begin{array}{l}\text { No. of } \\
\text { Items }\end{array}$ & 0 & 1 & 2 & 3 & 4 & 5 & 6 & 7 & 8 & 10 & 15 & 20 & 25 & 30 & 40 & 50 & 200 & Total \\
\hline $\begin{array}{l}\text { Freque } \\
\text { ncy }\end{array}$ & 207 & 20 & 76 & 35 & 48 & 60 & 1 & 7 & 1 & 18 & 2 & 1 & 1 & 2 & 1 & 1 & 1 & 482 \\
\hline $\begin{array}{l}\text { Percen } \\
\text { tage }\end{array}$ & 42.9 & 4.1 & 15.8 & 7.3 & 10 & $\begin{array}{c}12 . \\
4\end{array}$ & .2 & 1.5 & .2 & 3.7 & .4 & .2 & .2 & .4 & .2 & .2 & .2 & 100 \\
\hline
\end{tabular}

Software are considered to be an excellent 'inclusive material' for an effective functioning of an educational system. Premier educational institutions have started using software for instruction methods. In view of the table 1 of the study reveals that majority of the respondents of this research $42.9 \%(n=207)$ have not downloaded software, while $15.8 \%$ $(\mathrm{n}=76)$ download 2 software, $12.4 \%(\mathrm{n}=60)$ do 5 downloads, $10.0 \%(\mathrm{n}=48)$ download 4 software. A very less / negligible percentage was found in the other variables. This shows that the software downloading behavior among the university students were comparatively 
very low and a very less number/percentage of respondents alone were actively downloading the software from the social networking sites for their academic purpose.

\section{Table: 2: Downloads of Video Talks/Lectures from the internet per day by the students}

In this section researcher planned to study the video talks/lectures downloading behavior of the university students. Acquired data is presented below.

\begin{tabular}{|l|c|c|c|c|c|c|c|c|c|c|c|c|c|c|c|c|}
\hline No. of Items & 0 & 1 & 2 & 3 & 4 & 5 & 6 & 7 & 8 & 10 & 15 & 20 & 25 & 30 & 50 & Total \\
\hline Frequency & 337 & 16 & 31 & 20 & 18 & 22 & 2 & 4 & 2 & 16 & 6 & 4 & 1 & 1 & 2 & 482 \\
\hline Percentage & 69.9 & 3.3 & 6.4 & 4.1 & 3.7 & 4.6 & .4 & .8 & .4 & 3.3 & 1.2 & .8 & .2 & .2 & .4 & 100 \\
\hline
\end{tabular}

With features that allow users to upload photos and videos, and add or 'follow' links to external Web pages, social-networking sites provide students with photo narration, text narration, videos, audio tracks, and animations as useful resources for students to share and exchange study content.

As observed in this section a majority of the respondents of this research $69.9 \%(n=337)$ have not downloaded any video files. $6.4 \%$ of them $(n=31)$ download 2 files, $4.6 \%(n=22)$ download 5 media files, $4.1 \%(n=20)$ download 3 video files of different sorts. Only $0.2 \%$ $(n=1)$ of the respondents have downloaded 25 and 30 video files. Though the social networking sites have vast database of video files on various subjects, students did not download them for their academic development. The available data proves that significantly less percentage (around 29\%) of students alone downloaded video files for their academic excellence.

\section{Table: 3: Audio Books downloaded from the internet per day by the students}

The audio book downloading attitude among the university students were studied in this section and data presented in the Table 3.

\begin{tabular}{|l|c|c|c|c|c|c|c|c|c|c|}
\hline No. of Items & $0-7$ & 10 & 15 & 20 & 30 & 40 & 50 & 100 & 120 & Total \\
\hline Frequency & 464 & 8 & 4 & 1 & 1 & 1 & 1 & 1 & 1 & 482 \\
\hline Percentage & 96.1 & 1.7 & .8 & .2 & .2 & .2 & .2 & .2 & .2 & 100 \\
\hline
\end{tabular}


At the exponential growth of the electronic media, multimedia components invariably dominate the social media network of which audio and video are considered to be an important element in this domain. In this onset, this objective tends to study downloading of the audio lecture by the students. The study reveals that majority of the respondents of this research $96.1 \%(n=464)$ downloaded 0 to 7 items. $1.7 \%$ of them $(n=8)$ download 10 audio books, .8\% $(\mathrm{n}=4)$ do 15 downloads, only $0.2 \%(\mathrm{n}=1)$ of the respondents are downloading audio book 20, 30, 40, 50,100 and 120 of different sorts. Analyzed data intensely highlights that students have not been influenced by online audio books for academics.

\section{Table: 4: E-books downloaded from the internet per day by the students}

The Electronic book downloading habit of the students were studied in this section and obtained data were tabulated below.

\begin{tabular}{|l|c|c|c|c|c|c|c|c|c|c|c|c|c|c|}
\hline No. of Items & $0-10$ & 12 & 15 & 16 & 18 & 20 & 22 & 25 & 30 & 35 & 40 & 50 & 100 & Total \\
\hline Frequency & 286 & 2 & 92 & 1 & 1 & 53 & 1 & 31 & 10 & 1 & 2 & 1 & 1 & 482 \\
\hline Percentage & 59.2 & .4 & 19.1 & .2 & .2 & 11.0 & .2 & 6.4 & 2.1 & .2 & .4 & .2 & .2 & 100 \\
\hline
\end{tabular}

Social Networking Sites are considered to be a gold mine for electronic resources more particularly e-books are enhancing the uniqueness of the sites. The study reveals that majority of the respondents of this research 59.2\% $(n=286)$ downloaded less than 10 items, while $19.1 \%$ of them $(n=92)$ downloaded 15 e-books, $11.0 \%(n=53)$ do 20 downloads, $6.4 \%(n=$ 31) download 25 e-books of different sorts. Only $0.2 \%(n=1)$ of the respondents are downloading 16, 28, 50 and 100 e-books. It is clearly inferred that $40 \%$ of the students were alone actively involved in downloading the electronic books for the academic purposes.

\section{Table: 5: E-magazines downloaded from the internet per day by the students}

E-magazines downloading habit of the university students were observed, and obtained data were presented in the bellow stated table 5 .

\begin{tabular}{|l|c|c|c|c|c|c|c|c|c|c|c|c|}
\hline No. of Items & $0-5$ & 7 & 10 & 12 & 15 & 20 & 25 & 30 & 50 & 150 & 205 & Total \\
\hline Frequency & 373 & 6 & 58 & 2 & 21 & 14 & 4 & 1 & 1 & 1 & 1 & 482 \\
\hline Percentage & 77.5 & 1.2 & 12.0 & .4 & 4.4 & 2.9 & .8 & .2 & .2 & .2 & .2 & 100 \\
\hline
\end{tabular}


E-magazines are the most widely available features in the network. The study results indicates that majority of the respondents $77.5 \%(n=373)$ have downloaded only 0 to 5 items. $12.0 \%(\mathrm{n}=58)$ download 10 e-magazines, $4.4 \%(\mathrm{n}=21)$ download 15 e-magazines and $2.9 \%$ $(n=14)$ download 20 e-magazines of different sorts. Only $0.2 \%(n=1)$ of the respondents are downloading 30, 50,150 and 205 e-magazines. Unfortunately, the data reveals that around $80 \%$ of the students are unaware of the availability of the e-magazines in the social networking sites.

\section{Table: 6: E-Journals downloaded from the internet per day by the students}

The advent of new media technologies enables the researchers to access the research database instantly. The researcher has studied the e-journal downloading behavior of the students and the obtained data were presented below.

\begin{tabular}{|l|c|c|c|c|c|c|c|c|c|c|c|c|c|c|}
\hline $\begin{array}{l}\text { No. of } \\
\text { Items }\end{array}$ & $0-8$ & 10 & 12 & 15 & 18 & 20 & 25 & 30 & 40 & 50 & 55 & 60 & $>100$ & Total \\
\hline Frequency & 316 & 99 & 2 & 23 & 1 & 24 & 4 & 2 & 1 & 3 & 1 & 1 & 6 & 482 \\
\hline Percentage & 6.75 & 20.5 & .4 & 4.8 & .2 & 5.0 & .8 & .4 & .2 & .6 & .2 & .2 & 1.2 & 100 \\
\hline
\end{tabular}

The data identified that majority of the respondents $65.7 \%(n=316)$ have downloaded 0 to 8 items. $20.5 \%$ of them ( $n=99)$ download less than 10 e-journals, 5.0\% ( $\mathrm{n}=24)$ download less than 20 e-journals, $4.8 \%(n=23)$ download 15 e-journals of different sorts. Only $0.2 \%(n=1)$ of the respondents have downloaded more than 15 e-journals on a whole. Hence, it may be concluded that students were not actively engaging themselves in accessing e-journals from the social networking sites.

\section{Table: 7: E-Dissertations downloaded from the internet per day by the students}

The massive growth of new media technologies enable the users to access the electronic dissertations from the networks. The researcher has intended to know the e-dissertation downloading behavior of the university students and the collected data were presented below in the table.7

\begin{tabular}{|l|c|c|c|c|c|c|c|c|c|c|c|c|c|c|}
\hline No. of Items & $0-10$ & 12 & 13 & 15 & 20 & 25 & 30 & 35 & 40 & 50 & 55 & 60 & $>100$ & Total \\
\hline Frequency & 427 & 2 & 1 & 8 & 15 & 8 & 5 & 1 & 2 & 5 & 1 & 2 & 5 & 482 \\
\hline Percentage & 88.5 & .4 & .2 & 1.7 & 3.1 & 1.7 & 1.0 & .2 & .4 & 1.0 & .2 & .4 & 1.0 & 100 \\
\hline
\end{tabular}


The above table 7 reveals that majority of the respondents of this research $88.5 \%(n=427)$ downloaded less than 10 items. $3.1 \%$ of them $(n=15)$ download 20 e-dissertations, $1.7 \%$ $(n=8)$ download 25 e-dissertations, $1.7 \%(n=8)$ download 15 e-dissertations of different sorts. Only $0.2 \%(n=1)$ of the respondents have downloaded more than 55 e-dissertations. The sample has both masters and research students; hence the obtained data clearly shows that the students were not using the social networking sites for downloading e-dissertations for academic and research purposes.

\section{Table: 8: Research Articles downloaded from the internet per day by the students}

Collection of research articles/papers and related reviews are the customary and primary activity of a researcher. The new media technology and social networking sites forums are actively attracting the researchers to its sphere. In this aspect, the research article downloading behavior was measured among the university students and the findings are presented in the table 8.

\begin{tabular}{|l|c|c|c|c|c|c|c|c|c|c|c|c|c|c|c|c|}
\hline $\begin{array}{l}\text { No. of } \\
\text { Items }\end{array}$ & $0-8$ & 10 & 12 & 15 & 20 & 25 & 30 & 35 & 40 & 45 & 50 & 55 & 60 & 70 & $>100$ & Total \\
\hline Frequency & 152 & 46 & 1 & 18 & 48 & 89 & 51 & 10 & 25 & 7 & 20 & 1 & 3 & 4 & 7 & 482 \\
\hline Percentage & 31.6 & 9.5 & .2 & 3.7 & 10 & 18.5 & 10.6 & 2.4 & 5.1 & 1.5 & 4.1 & .2 & .6 & .8 & 1.4 & 100 \\
\hline
\end{tabular}

The above table reveals that $31.6 \%(n=152)$ have downloaded less than 8 research articles. $18.5 \%$ of them $(n=89)$ downloaded 25 articles, $10.6 \%(n=51)$ downloaded 30 articles and $10.0 \%(\mathrm{n}=48)$ downloaded 20 research articles of different sorts. An indiscernible percentage $0.2 \%(\mathrm{n}=1)$ of the respondents alone have downloaded more than 55 articles.

Table: 9: Power Point Templates (PPT) Files downloaded from the internet per day by the students

In this section, the researcher proposes to study the power point presentation (PPT) downloading behavior of university students for their academic benefit. The findings are presented in the Table 9.

\begin{tabular}{|l|l|l|l|l|l|l|l|l|l|l|l|}
\hline No. of Items & $0-6$ & 8 & 10 & 15 & 16 & 20 & 30 & 50 & 100 & 560 & Total \\
\hline
\end{tabular}




\begin{tabular}{|l|c|c|c|c|c|c|c|c|c|c|c|}
\hline Frequency & 378 & 1 & 57 & 24 & 1 & 14 & 3 & 2 & 1 & 1 & 482 \\
\hline Percentage & 78.4 & .2 & 11.8 & 5.0 & .2 & 2.9 & .6 & .4 & .2 & .2 & 100 \\
\hline
\end{tabular}

The table clearly states that majority of the respondents $78.4 \%(n=378)$ have downloaded less than 6 items. $11.8 \%$ of them $(n=57)$ have downloaded 10 PPT files, 5.0\% $(n=24)$ have downloaded 15 ppt files, $2.9 \%(n=14)$ have downloaded 20 ppt files. Only $0.2 \%(n=1)$ of the respondents have downloaded 8, 16, 100 and 560 PPT files.

\section{Conclusions}

The study on the academic usage of Social Networking sites by the University students' of Tamil Nadu delivers the existing pattern that there exists a reserved attitude in the using academic content through Social Media for academic excellence. While 'Google' is a universally accepted medium for searching all or any type of information through Internet, there is a growing trend of using Social Media for particular information. Today, Social Media is the new Google where one can create individual forums for detailed discussions relating to all fields of study. Social Media creates a platform for one on one and one to many interactions for pointed details about the subject and to enhance mastery over a subject. The prime users of the Social Media are students who have access to unlimited usage for they have more time and mind to focus on their pursuit of knowledge. But contrary to this belief, the results indicate that university students have very little exposure to use social media content into their academic life. Especially, with the study being conducted among the post graduate and research students, the results articulate how much 'non-inclusive' attitude is seen in the students in the usage of academic content present through the social networking sites. The downloading behavior of the university students viz, the usage of software, video and audio files, e-books, e-journals, e-dissertations, research articles and PPT presentations is disoriented from academics. This clearly points out the lack of awareness and the reservedly approach of students towards knowing the developments of their subject elsewhere and at the same time portrays the way they look upon social media. Hence, there is a need to educate the students on the potential use of Social Media by the educators. Social Media needs be given a new lease of life by the educators through separate curricula thus avoiding the fear and notion that Social Media is just a fun element. 


\section{References}

Barker, V. (2009). Older adolescents' motivations for social network site use: the influence of gender, group identity, and collective self-esteem. Cyber Psychology \& Behavior, 12(2), 209-213.

Chou, A. \& Chou, D. (2009). Information system characteristics and social network software adoption. Proceedings of the SWDSI conference, (pp. 335-343).

Dube, R. (2012). Characteristics of social networks. Retrieved July 8, 2014, from http://socialnetworking.lovetoknow.com/Characteristics of Social Networks

Garton, L., Haythornthwaite, C., \& Wellman, B. (1997). Studying online social networks. Journal of Computer-Mediated Communication, 3(1), Retrieved January 15, 2008, from http://jcmc.indiana.edu/vol3/issue1/garton.html

Gross, R. \& Acquisti, A. (2005). Information revelation and privacy in online social networks. In Proceedings of the WPES'05, 71-80.

Har Singh and Anil Kumar (2013). Use of social networking sites (SNSs) by the research scholars of Panjab University, Chandigarh: A study. 58th International Conference on: $\quad$ Next Generation Libraries: New insights and Universal Access to Knowledge. 682-691.

Internet \& Mobile Association of India (2011). Retrieved from http://www.iamai.in/PRelease_detail.aspx?nid=3240\&NMonth=1\&NYear=2014

Ipsos Open Thinking Exchange (2013). Retrieved from http://ipsos-na.com/newspolls/pressrelease.aspx $? \mathrm{id}=5954$

Kalpidou, M., Costin, D., \& Morris, J. (2011). The relationship between Facebook and the well- being of undergraduate college students. Cyber psychology, Behavior, and Social Networking, 14(4), 183-189.

Karpinski, A.C., \& Kirschner, P.A. (2010). Facebook and academic performance. Computers in Human Behavior, 26:1237-1245.

Lenhart, A., \& Madden, M. (2007). Teens, privacy \& online social networks: How teens manage their online identities and personal information in the age of MySpace. Pew Internet \& American Life Project.

Manjunatha, S. (2013). The Usage of Social Networking Sites among the College Students in India. International Research Journal of Social Sciences, 2(5), 15-21.

Martin, C. (2009). Social networking usage and grades among college students. UNH Media Relations. UNH Whitte more School of Business and Economics. 
Mazman, S. \& Usluel, Y. (2010). Modelling educational usage of Facebook. Computers \& Education, 55(2), 444-453.

Mislove, A., Marcon M., Gummadi K., Druschel P., \& Bhattacharjee B. (2007).Measurement and analysis of online social networks. Proceedings of Internet Measurement Conference.

Ou, C., Davison, R., \& Cheng, N. (2011). Why are social networking applications successful: an empirical study of Twitter. PACIS 2011 Proceedings. Paper. 145.

Richter, A. \& Koch, M. (2008). Functions of social networking services. The Proceeding of the 8th International Conference on the Design of Cooperative Systems, 87-98.

San Miguel, Renay (2010). "Study on Facebook and Grades Becomes Learning Experience for Researcher."TechNewsWorld.

http://www.technewsworld.com/rsstory/66805.html?wlc=1286985671\&wlc=1287195 47

Stollak, M. J., Vandenberg, A., Burklund, A., \& Weiss, S. (2011). Getting Social: The Impact of Social Networking Usage on grades Among College Students. ASBBS, 18(1), 859-865.

Walsh, J. L., Fielder, R. L., Carey, K. B., \& Carey, M. P. (2013). Female College Students' Media Use and Academic Outcomes Results From a Longitudinal Cohort Study. Emerging Adulthood.

Williams, A. \& Merten, M. (2008). A review of online social networking profiles by adolescents: implications for future research and intervention. Adolescence, 43 (170), 253-274.

$* * * * * * * * * * * * * * *$

This work was part of the Social Media Project funded by Indian Council of Social Sciences Research (ICSSR) MHRD, New Delhi, India. 